\title{
Archives of Allergy \\ and Immunology
}

Int Arch Allergy Immunol 2021;182:220-228

DOI: $10.1159 / 000510789$
Received: June 5, 2020

Accepted: August 10, 2020

Published online: November 11, 2020

\section{Factors Influencing Total Serum IgE in Adults: The Role of Obesity and Related Metabolic Disorders}

\author{
lago Carballo ${ }^{a}$ Manuela Alonso-Sampedro ${ }^{b}$ Elena Gonzalez-Conde ${ }^{a}$ \\ Juan Sanchez-Castro ${ }^{c}$ Carmen Vidal $^{d} \quad$ Francisco Gude $^{b} \quad$ Arturo Gonzalez- \\ Quintela $^{a}$
}

aDepartment of Internal Medicine, Complejo Hospitalario Universitario, Instituto de Investigaciones Sanitarias of Santiago de Compostela, Santiago de Compostela, Spain; bepartment of Clinical Epidemiology, Complejo Hospitalario Universitario, Instituto de Investigaciones Sanitarias of Santiago de Compostela, Santiago de

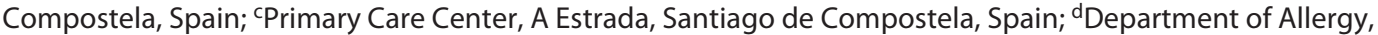
Complejo Hospitalario Universitario, Instituto de Investigaciones Sanitarias of Santiago de Compostela, Santiago de Compostela, Spain

\section{Keywords}

Immunoglobulin E · Atopy · Obesity · Metabolic syndrome · Alcohol $\cdot$ Smoking

\begin{abstract}
Background and Aim: Few reports have investigated the association between metabolic abnormalities (obesity and related metabolic syndrome) and total serum IgE concentrations. Methods: This cross-sectional study included a random sample of 1,516 adult individuals $(44.7 \%$ men, aged 18-91 years, median 52 years) from a single municipality in Spain. Serum IgE was measured in the ADVIA Centaur system. Atopy was defined by the presence of positive skin prick tests to a panel of common aeroallergens in the area. Body mass index and data related to the definition of metabolic syndrome were obtained from all participants. Alcohol consumption, smoking, and regular physical exercise were assessed by a questionnaire. Results: Atopy (present in 21.9\% of 1,514 evaluable individuals) was the strongest factor determining serum IgE concentrations. Male sex and heavy al-
\end{abstract}

cohol drinking were independently associated with higher IgE concentrations, particularly in the non-atopic individuals. Body mass index was positively associated with IgE concentrations, independent of potential confounders, although the effect was only evident among non-atopic individuals. In that group, median IgE concentrations in normal-weight and obese individuals were 15 and $24 \mathrm{kU} / \mathrm{L}$, respectively $(p<0.001)$; likewise, obesity was associated with high (>100 kU/L) IgE concentrations after adjusting for potential confounders (odds ratio: 1.79, 95\% confidence interval: $1.26-2.56, p=0.001)$. The presence of metabolic syndrome and its components, particularly abdominal obesity and hyperglycaemia, was also positively and independently associated with higher IgE concentrations in non-atopic individuals. Conclusions: Obesity and metabolic syndrome components are associated with high total serum IgE concentrations, particularly in non-atopic individuals.

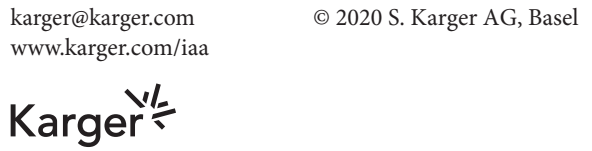

Arturo Gonzalez-Quintela

Department of Internal Medicine, Faculty of Medicine

Complejo Hospitalario Universitario de Santiago, Travesia da Choupana

ES-15706 Santiago de Compostela (Spain)

arturo.gonzalez.quintela@ sergas.es 


\section{Introduction}

Total serum immunoglobulin E (IgE) is a common diagnostic measurement in standard clinical practice in allergy clinics, and it is higher in atopic individuals [1-4]. Among adults, total serum IgE concentrations can also be influenced by a number of both modifiable and nonmodifiable factors. Among the latter, serum total IgE concentrations are higher in males and tend to decrease with ageing [1-4]. Among modifiable factors, helminth infection is a prominent cause of total IgE elevation, particularly in some parts of the world [1,2]. Total serum IgE is higher among alcohol drinkers (particularly, alcohol abusers) [5-7] and among smokers [8]. Moreover, increased total serum IgE concentrations have been reported in a number of non-allergic diseases $[1,2]$.

The potential effect of obesity and its related metabolic abnormalities on total serum IgE concentrations has been scarcely studied. Hence, obesity is not included in the usual lists of diseases associated with higher total serum $\operatorname{IgE}[1,2]$. Obesity is a growing epidemic contributing to significant disease burden worldwide [9]. Obesity and metabolic syndrome (a constellation of features associated with insulin resistance, including an excess of abdominal fat, hyperglycaemia, hypertension, and lipid abnormalities) represent a pro-inflammatory state that includes abnormalities in cytokines that are involved in IgE synthesis such as IL-4 and IL-13 [10-14]. Kim et al. [15] observed that total serum IgE concentrations were weakly but significantly correlated with BMI, waist circumference, systolic blood pressure, and triglyceride level in a sample of 1,528 Korean adults [15]. Likewise, Park et al. [16] reported an association between obesity and total serum IgE in another sample of 1,577 Korean adults older than 30 years. Similarly, Visness et al. [17] reported that total serum IgE was higher in those with obesity and overweight than in normal-weight individuals in a sample of 4,111 USA children and young adolescents. However, Jarvis et al. [18] stated that no association between BMI and total IgE was present in the 15,454 participants of a multicentre cross-sectional survey of young adults from Europe, the USA, and Australia-New Zealand although the precise data were not reported [18]. Importantly, none of these studies stratified their samples by the results of skin prick tests (SPT) as a definition of atopy. The present study was aimed at investigating the potential influence of obesity and related metabolic abnormalities on total serum IgE levels in a general adult population, stratified by atopy as defined by positive SPTs and after adjusting for potential confounders.

\section{Methods}

Design

This is a cross-sectional study that was developed in the municipality of A-Estrada (Spain, location $42^{\circ} 41^{\prime} 21^{\prime \prime} \mathrm{N}, 8^{\circ} 29^{\prime} 14^{\prime \prime} \mathrm{W}$ ), as has been reported elsewhere [19]. The A-Estrada Glycation and Inflammation Study (AEGIS) is available at www.clinicaltrials.gov, code NCT01796184. The study included an age-stratified sample of the general adult population (Fig. 1 ) from the municipality $(n=$ $1,516)(44.7 \%$ men; median age 52 years, range $18-91$ years). All participants were Caucasian. The study was approved by the Regional Ethics Committee (code 2010-315). Written informed consent was obtained from all participants.

\section{Main Outcome Measure: Total Serum IgE}

The determination of total IgE was made with the ADVIA Centaur Total IgE assay (Siemens Healthcare Diagnostics, Los Angeles, CA, USA), a two-site sandwich immunoassay using direct chemiluminometric technology. According to the manufacturer, the analytical measuring range of the assay is $1.5-3,000 \mathrm{kU} / \mathrm{L}$. Serum samples with IgE levels $>3,000 \mathrm{IU} / \mathrm{mL}$ were diluted and retested to obtain accurate results. The expected values for adults range from 0 to $378 \mathrm{kU} / \mathrm{L}$ with a geometric mean of $17 \mathrm{kU} / \mathrm{L}$.

\section{Definition of Metabolic Abnormalities}

BMI was calculated as weight (in kilogrammes) divided by the square of height (in metres). Participants were classified as having normal weight $\left(<25 \mathrm{~kg} / \mathrm{m}^{2}\right)$, overweight $\left(25-30 \mathrm{~kg} / \mathrm{m}^{2}\right)$, or obesity $\left(>30 \mathrm{~kg} / \mathrm{m}^{2}\right)$. Participants were considered as having metabolic syndrome when they met at least 3 of the following Adult Treatment Panel III criteria [20]: (a) abdominal obesity (waist circumference $>102 \mathrm{~cm}$ in men or $>88 \mathrm{~cm}$ in women); (b) hypertriglyceridaemia (fasting serum triglycerides $\geq 150 \mathrm{mg} / \mathrm{dL}$ ); (c) low HDL cholesterol levels (fasting HDL cholesterol $<40 \mathrm{mg} / \mathrm{dL}$ in men or $<50 \mathrm{mg} / \mathrm{dL}$ in women); (d) increased blood pressure (arterial blood pressure $\geq 130 / \geq 85 \mathrm{~mm} \mathrm{Hg}$ or current antihypertensive medication use); and (e) hyperglycaemia (fasting serum glucose $\geq 110 \mathrm{mg}$ / $\mathrm{dL}$ or current anti-diabetic therapy).

\section{Assessment of Atopy}

A panel of SPT to relevant aeroallergens in the area was performed on all participants. The panel included house dust mites (Dermatophagoides pteronyssinus and Lepidoglyphus destructor), pollens (Phleum pratense, Plantago lanceolata, Betula alba, and Parietaria judaica), vegetable panallergens (profilin and peach lipid transfer protein), moulds (Alternaria alternata and Aspergillus spp.), and animal dander (dog and cat) (ALK-Abelló, Spain). The control SPT included $10 \mathrm{mg} / \mathrm{mL}$ histamine and saline solution. Standard procedures were followed [21]. Wheals with a mean diameter $>3 \mathrm{~mm}$ after $15 \mathrm{~min}$ were deemed positive. The presence of at least 1 positive SPT was considered indicative of allergic sensitization or atopy [22].

\section{Assessment of Alcohol Consumption}

Alcohol consumption was evaluated in standard drinking units [23] by summing the number of glasses of wine ( 1 unit, $\sim 10 \mathrm{~g}$ ), bottles of beer (1 unit, $\sim 10 \mathrm{~g}$ ), and spirits ( 2 units, $\sim 20 \mathrm{~g}$ ) regularly consumed per week. Individuals with an alcohol consumption of 1-13 units/week were considered as light drinkers, those with an alcohol consumption of 14-27 units/week were considered 


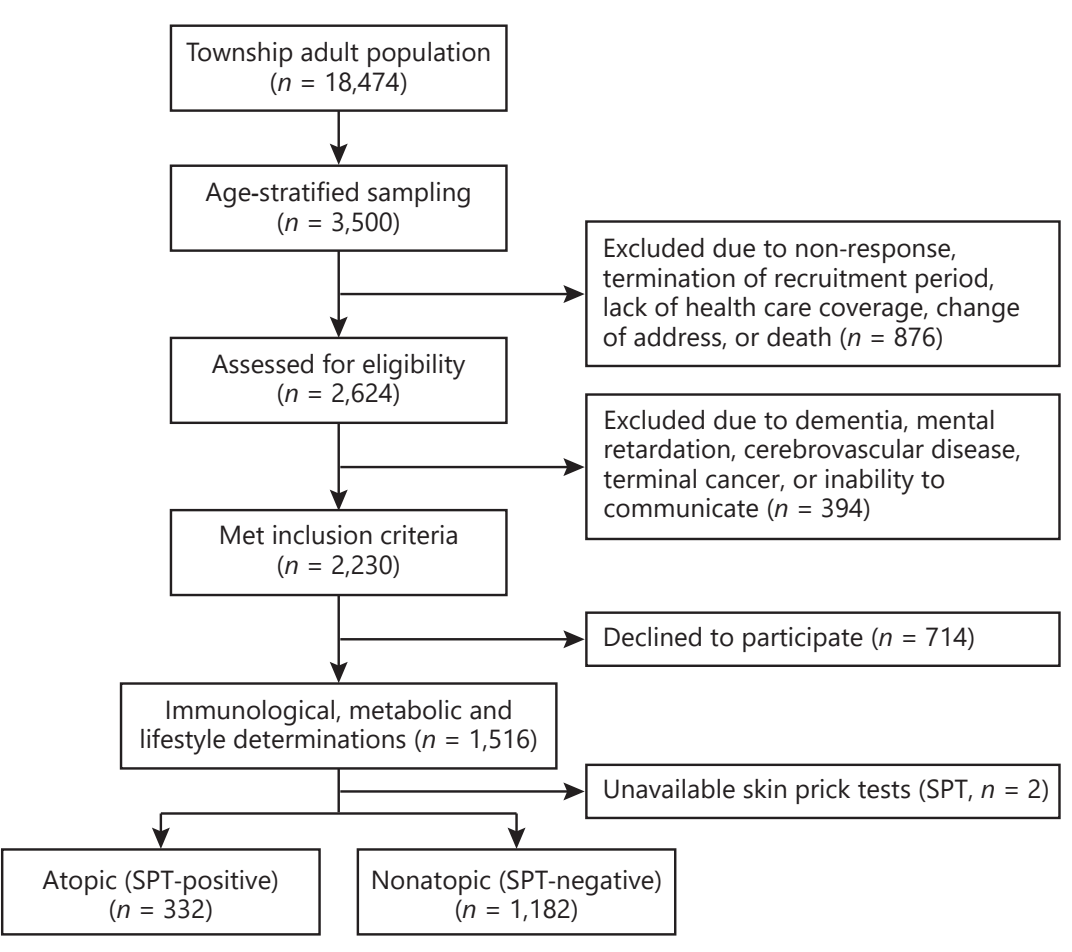

Fig. 1. Study profile. SPTs, skin prick tests.

as moderate drinkers, and those with an alcohol consumption $\geq 28$ units/week were defined as heavy drinkers. The remainder, comprising alcohol abstainers and occasional alcohol drinkers, were included together in the same group.

\section{Assessment of Smoking}

Consumers of at least 1 cigarette per day were considered to be smokers. Individuals who had quit smoking during the preceding year were still considered smokers, whereas those who had quit more than 1 year prior to the study were considered ex-smokers.

\section{Assessment of Physical Activity}

All study participants completed the International Physical Activity Questionnaire (short version). The questionnaire is freely available at https://sites.google.com/site/theipaq/home and has been validated in Spain [24]. The questionnaire allows for the calculation of Metabolic Equivalents of Task and for stratification of habitual physical activity as low, moderate, or high, as previously described [19].

\section{Statistical Analyses}

The Kolmogorov-Smirnov test was used to assess the normal distribution of variables. The Mann-Whitney test was used to compare numerical variables. The Jonckheere-Terpstra test for trend was used to compare numerical variables in ordinal categories. Spearman's rank test was used to assess correlation. Linear regression was used for multivariate analysis of factors associated with IgE concentrations. For that purpose, IgE values were $\log _{10}$ transformed in order to normalize their distribution. For logarithmic transformation, cases with undetectable $\operatorname{IgE}(n=51)$ were at- tributed an arbitrary value of $1 \mathrm{kU} / \mathrm{L}$. Logistic regression was used for multivariate analysis of factors associated with high $(>100$ $\mathrm{kU} / \mathrm{L}$ ) IgE concentrations. Variables were forced to enter the equation in all multivariate models. $p$ values $<0.05$ were deemed statistically significant.

\section{Results}

\section{General Distribution of Total Serum IgE}

Median serum IgE in the whole study population was $28 \mathrm{kU} / \mathrm{L}$ (interquartile range [IQR]: 8-87 kU/L, absolute range $<1-5,762 \mathrm{kU} / \mathrm{L})$. A total of $346(22.8 \%)$ individuals showed IgE values higher than $100 \mathrm{kU} / \mathrm{L}$. The distribution of serum IgE was highly skewed (test for normality, $p<0.001)$, but tended to adopt a normal distribution after $\log _{10}$ transformation $(p=0.240)$.

\section{Influence of Atopy}

The SPT results were available for 1,514 individuals (they were not available in 2 cases due to current antihistamine medication); 332 individuals (21.9\%) were atopic (SPT positive). Mites were the most common sensitizers in the area (data not shown). Atopic individuals showed much higher IgE concentrations than non-atopic individuals (median: $113 \mathrm{kU} / \mathrm{L}$ and IQR: $41-274 \mathrm{kU} / \mathrm{L}$ vs. me- 
Table 1. Total serum IgE in relation to age, sex, and lifestyle factors in atopic and non-atopic individuals

\begin{tabular}{|c|c|c|c|c|c|c|}
\hline \multirow[t]{2}{*}{ Factor } & \multicolumn{3}{|c|}{ Non-atopic $(n=1,182)$} & \multicolumn{3}{|c|}{ Atopic $(n=332)$} \\
\hline & no & $\operatorname{IgE}(\mathrm{kU} / \mathrm{L})$ & $p$ value & no & $\operatorname{IgE}(\mathrm{kU} / \mathrm{L})$ & $p$ value \\
\hline \multicolumn{7}{|l|}{ Sex } \\
\hline Females & 668 & $14(5-41)$ & Ref & 148 & $99(28-228)$ & Ref \\
\hline Males & 494 & $27(10-79)$ & $<0.001$ & 184 & $133(49-311)$ & 0.014 \\
\hline \multicolumn{7}{|l|}{ Age, years } \\
\hline $18-35$ & 163 & $16(6-43)$ & Ref & 132 & $140(41-254)$ & Ref \\
\hline$>35-50$ & 296 & $16(5-40)$ & 0.468 & 116 & $99(41-309)$ & 0.882 \\
\hline$>50-65$ & 346 & $24(8-68)$ & 0.033 & 45 & $80(31-190)$ & 0.236 \\
\hline$>65$ & 377 & $21(6-61)$ & 0.174 & 39 & $138(51-365)$ & 0.727 \\
\hline \multicolumn{7}{|l|}{ Alcohol consumption } \\
\hline Abstainers & 435 & $14(5-41)$ & Ref & 110 & $110(28-246)$ & Ref \\
\hline Light drinkers & 448 & $20(7-52)$ & 0.004 & 150 & $93(38-253)$ & 0.800 \\
\hline Moderate drinkers & 196 & $27(8-58)$ & $<0.001$ & 45 & $180(60-287)$ & 0.268 \\
\hline Heavy drinkers & 103 & $44(13-132)$ & $<0.001$ & 27 & $169(91-512)$ & 0.025 \\
\hline \multicolumn{7}{|l|}{ Smoking } \\
\hline Never smokers & 670 & $16(6-46)$ & Ref & 154 & $107(37-244)$ & Ref \\
\hline Ex-smokers & 313 & $24(9-66)$ & $<0.001$ & 82 & $137(58-285)$ & 0.173 \\
\hline Current smokers & 199 & $22(8-69)$ & 0.003 & 96 & $102(36-275)$ & 0.911 \\
\hline \multicolumn{7}{|l|}{ Physical activity } \\
\hline Low & 485 & $20(6-58)$ & Ref & 109 & $104(41-227)$ & Ref \\
\hline Moderate & 431 & $17(6-45)$ & 0.076 & 121 & $98(41-250)$ & 0.958 \\
\hline High & 266 & $22(8-54)$ & 0.647 & 102 & $162(40-358)$ & 0.135 \\
\hline
\end{tabular}

Data are medians and interquartile (25th-75th percentile) ranges (in brackets). Ref, reference category.

dian: $19 \mathrm{kU} / \mathrm{L}$ and IQR: 6-53 kU/L, respectively, $p<$ 0.001 ). Among atopic individuals, higher IgE concentrations were observed among those with respiratory (nasal and/or bronchial) symptoms (data not shown). Atopy was the strongest predictor of IgE variability in this population. Thus, the effect of additional covariates was stratified into atopic and non-atopic individuals (Table 1).

\section{Influence of Demographic Factors (Age and Sex)}

In the univariate analyses, men showed higher IgE concentrations than women, both among atopic and non-atopic individuals (Table 1). The positive association of male sex with IgE concentrations was maintained in multivariate analyses after adjusting for potential confounders in the non-atopic individuals (Table 2). The effect of age (in categories) on serum IgE concentrations was less evident (Table 1). Among non-atopic individuals, there was a trend toward an increase in IgE concentrations with the advancing age category $(p=0.009$, trend test) (Table 1). A similar trend was not observed among atopic individuals (Table 1). Accordingly, there was a statistically significant, positive correlation between age (in years) and serum IgE among the non-atopic (rho 0.134, $p<0.001$ ) but not among the atopic individuals (rho $-0.029, p=0.601)$. In multivariate analyses, the association of age with higher IgE concentrations was statistically significant in the non-atopic, but not in the atopic individuals (Table 2).

Influence of Lifestyle Factors (Exercise, Smoking, and Alcohol Consumption)

There was no significant association between physical activity and IgE concentrations (Table 1 ) either among atopic ( $p=0.128$, trend test) or non-atopic ( $p=0.937$, trend test) individuals. Current smoking was associated with higher IgE concentrations among non-atopic individuals in the univariate analyses (Table 1). Even exsmokers showed higher IgE concentrations than never smokers (Table 1). Such an association, however, was not evident among atopic individuals (Table 1). In the multivariate analyses, the association between smoking and higher IgE concentrations was statistically significant in non-atopic, but not in atopic individuals (Table 2).

Alcohol consumption, particularly heavy drinking, was associated with higher IgE concentrations in the uni- 
Table 2. Multivariate analysis: linear regression of serum $\operatorname{IgE}\left(\log _{10}\right.$ transformed) in relation to demographics, lifestyle factors, and BMI in participants stratified by atopy

\begin{tabular}{|c|c|c|c|c|}
\hline \multirow[t]{2}{*}{ Covariate } & \multicolumn{2}{|c|}{ Non-atopic $(n=1,182)$} & \multicolumn{2}{|l|}{ Atopic $(n=332)$} \\
\hline & coefficient (SE) & $p$ value & coefficient (SE) & $p$ value \\
\hline \multicolumn{5}{|l|}{ Sex } \\
\hline Female & Ref & NA & Ref & NA \\
\hline Male & $0.176(0.045)$ & $<0.001$ & $0.139(0.079)$ & 0.078 \\
\hline Age (years) & $0.003(0.001)$ & 0.036 & $-0.002(0.002)$ & 0.505 \\
\hline \multicolumn{5}{|l|}{ Alcohol consumption } \\
\hline Abstainers & Ref & NA & Ref & NA \\
\hline Light drinkers & $0.074(0.044)$ & 0.099 & $-0.064(0.081)$ & 0.434 \\
\hline Moderate drinkers & $0.071(0.059)$ & 0.230 & $0.002(0.118)$ & 0.988 \\
\hline Heavy drinkers & $0.243(0.077)$ & 0.001 & $0.273(0.145)$ & 0.060 \\
\hline \multicolumn{5}{|l|}{ Smoking } \\
\hline Never smokers & Ref & NA & Ref & NA \\
\hline Ex-smokers & $0.080(0.047)$ & 0.088 & $0.056(0.089)$ & 0.528 \\
\hline Current smokers & $0.167(0.056)$ & 0.003 & $-0.049(0.085)$ & 0.569 \\
\hline \multicolumn{5}{|l|}{ Physical activity } \\
\hline Low & Ref & NA & Ref & NA \\
\hline Moderate & $-0.054(0.043)$ & 0.211 & $-0.025(0.083)$ & 0.762 \\
\hline High & $0.024(0.050)$ & 0.634 & $0.105(0.088)$ & 0.236 \\
\hline BMI $\left(\mathrm{kg} / \mathrm{m}^{2}\right)$ & $0.014(0.004)$ & $<0.001$ & $-0.008(0.008)$ & 0.335 \\
\hline Constant (intercept) & $0.581(0.126)$ & NA & $2.219(0.228)$ & NA \\
\hline
\end{tabular}

For logarithmic transformation, cases with undetectable $\operatorname{IgE}(n=51)$ were attributed an arbitrary value of 1 $\mathrm{kU} / \mathrm{L}$. All listed covariates entered the equation. Covariates explained 7.7\% $\left(R^{2} 0.077\right)$ and $5.3 \%(\mathrm{R} 20.053)$ of the variability of IgE in non-atopic and atopic individuals, respectively. Atopy per se explained $18.2 \%$ of the variability of IgE when all individuals are introduced in the model. NA, not applicable; Ref, reference category.

variate analyses, in both atopic and non-atopic individuals (Table 1). Among the non-atopic individuals, there was a significant trend toward higher IgE concentrations with the increasing alcohol consumption category $(p<$ 0.001 , trend test). Even light-to-moderate drinkers showed higher IgE concentrations than abstainers (Table 1). Among the atopic individuals, this trend was not significant $(p=0.055)$, and only heavy drinkers showed higher IgE concentrations than abstainers (Table 1). In the multivariate analyses, the association between heavy drinking and higher IgE concentrations was statistically significant in the non-atopic, but not in the atopic group (Table 2).

\section{Influence of Metabolic Abnormalities (Obesity and \\ Metabolic Syndrome)}

The univariate analyses of serum IgE concentrations in relation to BMI and related metabolic abnormalities are shown in Table 3. In the non-atopic group, obese individuals showed higher IgE concentrations than their normal-weight counterparts. Obese individuals showed a median IgE concentration that was $60 \%$ higher than that of normal-weight individuals (Table 3). Obesity in the non-atopic group was associated with high $(>100$ $\mathrm{kU} / \mathrm{L}$ ) IgE concentrations after adjusting for confounders including age, sex, smoking, alcohol consumption, and physical activity (OR: 1.79, 95\% CI: 1.26-2.56, $p=$ $0.001)$. These differences were not observed in the atopic group (Table 3). Among non-atopic individuals, there was a trend toward an increase in $\operatorname{IgE}$ concentrations with the advancing BMI category ( $p=0.001$, trend test) (Table 3$)$. A similar trend was not observed among atopic individuals $(p=0.693)$. Accordingly, there was a positive correlation between BMI (in $\mathrm{kg} / \mathrm{m}^{2}$ ) and serum IgE in the non-atopic group (rho 0.134, $p<0.001$ ) but not among atopic individuals (rho $-0.029, p=0.601$ ). In the multivariate analyses, the association between BMI and higher IgE concentrations was statistically significant in the non-atopic group, but not in the atopic group (Table 2).

Obesity was closely associated with the presence of metabolic syndrome (data not shown). Similar to obesi- 
Table 3. Total serum IgE in relation to BMI, presence of metabolic syndrome, and its components in atopic and non-atopic individuals

\begin{tabular}{|c|c|c|c|c|c|c|}
\hline \multirow[t]{2}{*}{ Factor } & \multicolumn{3}{|c|}{ Non-atopic $(n=1,182)$} & \multicolumn{3}{|c|}{ Atopic $(n=332)$} \\
\hline & no & $\operatorname{IgE}(\mathrm{kU} / \mathrm{L})$ & $p$ value & no & $\operatorname{IgE}(\mathrm{kU} / \mathrm{L})$ & $p$ value \\
\hline \multicolumn{7}{|l|}{ BMI } \\
\hline Normal weight & 305 & $15(5-42)$ & Ref & 117 & $114(40-285)$ & Ref \\
\hline Overweight & 447 & $18(6-47)$ & 0.573 & 127 & $109(45-268)$ & 0.831 \\
\hline Obese & 430 & $24(8-70)$ & $<0.001$ & 88 & $115(30-262)$ & 0.625 \\
\hline \multicolumn{7}{|c|}{ Metabolic syndrome } \\
\hline No & 920 & $18(6-47)$ & Ref & 280 & $113(41-266)$ & Ref \\
\hline Yes & 262 & $26(8-74)$ & $<0.001$ & 52 & $118(41-447)$ & 0.683 \\
\hline \multicolumn{7}{|l|}{ Abdominal obesity } \\
\hline No & 615 & $17(6-44)$ & Ref & 239 & $108(41-260)$ & Ref \\
\hline Yes & 566 & $22(7-61)$ & 0.004 & 93 & $135(41-322)$ & 0.583 \\
\hline \multicolumn{7}{|l|}{ High blood pressure } \\
\hline No & 534 & $16(5-42)$ & Ref & 210 & $110(38-246)$ & Ref \\
\hline Yes & 648 & $24(8-65)$ & $<0.001$ & 122 & $119(46-356)$ & 0.248 \\
\hline \multicolumn{7}{|l|}{ Hyperglycaemia } \\
\hline No & 957 & $18(6-46)$ & Ref & 299 & $115(41-274)$ & Ref \\
\hline Yes & 225 & $31(10-89)$ & $<0.001$ & 33 & $109(39-231)$ & 0.572 \\
\hline \multicolumn{7}{|c|}{ Hypertriglyceridaemia } \\
\hline No & 970 & $18(6-50)$ & Ref & 261 & $114(41-267)$ & Ref \\
\hline Yes & 208 & $22(8-67)$ & 0.054 & 89 & $112(41-396)$ & 0.893 \\
\hline \multicolumn{7}{|c|}{ Low HDL cholesterol } \\
\hline No & 972 & $20(6-53)$ & Ref & 276 & $114(41-268)$ & Ref \\
\hline Yes & 210 & $17(6-51)$ & 0.720 & 55 & $108(35-436)$ & 0.869 \\
\hline
\end{tabular}

Data are medians and interquartile (25th-75th percentile) ranges (in brackets). Ref, reference category.

ty, metabolic syndrome was associated with higher $\operatorname{IgE}$ concentrations among non-atopic individuals in the univariate analyses (Table 3). In the multivariate analyses (linear regression), the presence of metabolic syndrome was positively associated with total serum IgE after adjusting for confounders, including atopy, age, sex, alcohol consumption, smoking, and physical activity ( $p=$ 0.003). Among metabolic syndrome components, abdominal obesity, hyperglycaemia, and high blood pressure were significantly associated with higher IgE concentrations in the univariate analyses in the non-atopic group (Table 3). In that group, there was a significant trend toward increasing serum IgE concentrations in relation to the number of metabolic syndrome criteria (from 0 to 5) in a given individual (Fig. 2). Among metabolic syndrome criteria, abdominal obesity and hyperglycaemia were associated with total serum IgE after adjusting for atopy, age, sex, alcohol consumption, smoking, and physical activity $(p=0.011$ and $p=0.002$, respectively).

$\operatorname{IgE}$ and Obesity

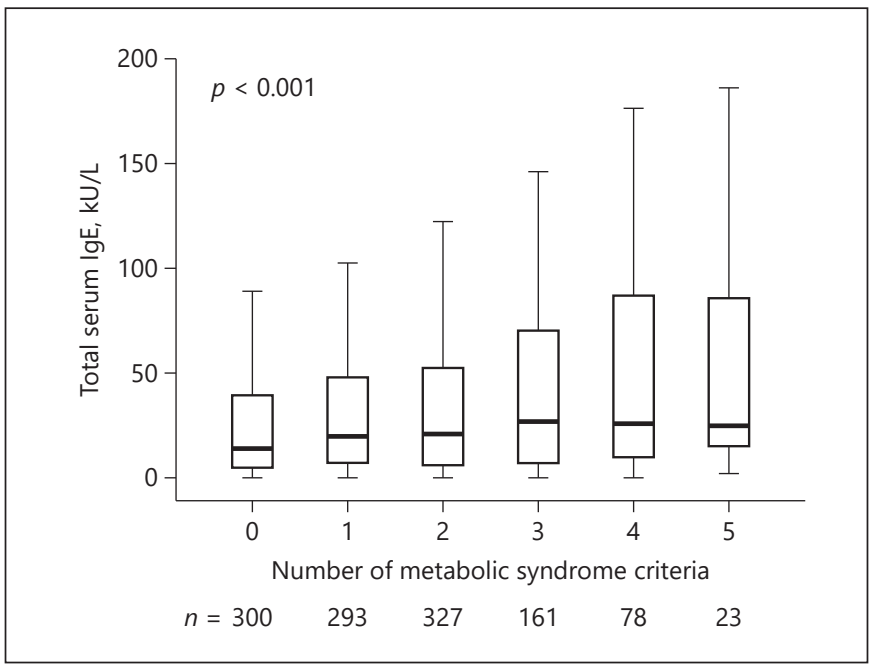

Fig. 2. Boxplot of total serum IgE concentrations in non-atopic individuals in relation to the number of metabolic syndrome criteria per individual. Outliers (values outside 1.5 times the IQR above the upper quartile and below the lower quartile) are not represented but are included in the analysis. The $p$ value was obtained with the Jonckheere-Terpstra test for trend.

Int Arch Allergy Immunol 2021;182:220-228 


\section{Discussion}

The present study confirms that atopy is the strongest factor associated with high total serum IgE concentrations in adults $[1,2]$. Furthermore, it confirms that male sex, smoking, and heavy alcohol drinking are associated with higher IgE concentrations [1-8], particularly in non-atopic individuals. Variability of $\operatorname{IgE}$ is higher in atopic than in non-atopic individuals, and data dispersion may induce that differences related to a given factor become no statistically significant in the former group. This is the case of alcohol consumption, whose effect is similar in atopic and non-atopic individuals, but is only significant in the non-atopic group, as previously described [5]. Ageing was associated with higher IgE concentrations after adjusting for confounders among nonatopic individuals. This is in contrast with the general finding of lower IgE concentrations with advancing age although the reported effect is modest $[2,4]$ and restricted to females in some studies [3]. In addition to these well-known factors influencing total serum IgE levels, the present study shows that obesity and the closely linked metabolic syndrome are independently associated with increased serum IgE concentrations, particularly in nonatopic individuals. To the best of our knowledge, this is the 1st study showing this effect and the difference between atopic and non-atopic individuals in a Caucasian adult population using the results of SPTs as criteria for atopy. The same effect was not observed in atopic individuals.

Obesity has been found to be consistently associated with asthma and asthma severity [25-28]; however, its relationship with atopy, as defined by the presence of serum specific IgE or SPT to aeroallergens, is controversial, particularly in adults $[18,25,29-33]$. In the present study, we found no significant association between obesity or metabolic syndrome and atopy as defined by positive SPTs (data not shown). The potential relationship of obesity and related metabolic abnormalities with total serum IgE was also controversial. Previous studies in Asian adult populations reported an association between diverse measures of obesity with high IgE levels $[15,16]$. In young adults from Europe, North America, and Oceania, however, no association between obesity and IgE was reported although precise data were not given [18]. However, none of these studies made the distinction between atopic and non-atopic individuals. Therefore, it is not possible to know if such an association had become evident when stratifying for atopy. Metabolic syndrome was associated with increased IgE in the Korean population [15]. In this population, the association was also observed with metabolic syndrome components such as central obesity, hyperglycaemia, high blood pressure, and high serum triglycerides [15]. In contrast, HDL cholesterol levels were negatively associated with IgE [15]. Likewise, total serum IgE has been found increased in smaller samples of patients with diabetes and pre-diabetes with respect to normoglycaemic individuals $[34,35]$. This association, however, was not observed in other studies [36]. In our study, abdominal obesity and hyperglycaemia were independently associated with higher IgE concentrations in non-atopic individuals. The potential mechanisms for the association between obesity, metabolic syndrome, and IgE are not known. In our experience, this association in nonatopic individuals was independent of age, sex, alcohol consumption, smoking, and regular physical exercise. Obesity and metabolic syndrome are pro-inflammatory states [10-14]. It could be argued that the imbalance in the production of cytokines with a Th2 predominance in these states could favour the synthesis of IgE [37]. Metabolic syndrome is a constellation of components with underlying insulin resistance [20]. Cytokine imbalance may vary depending on the component considered $[38,39]$ and could explain their different association with serum IgE concentrations. Alternatively, causality could be the reverse. Kim et al. [15] argue that the elevation of IgE could favour the development of metabolic disorders Mast cell activation might be involved in the development of metabolic disorders [40]. Along these lines, increased $\operatorname{IgE}$ and subsequent mast cell activation have been found related to ischaemic heart disease [41]. Moreover, IgE may contribute to obesity and atherosclerosis in mice [42]. Further studies would be required to elucidate the mechanisms of elevation of total serum IgE in these metabolic disorders.

This study has limitations that should be acknowledged. In particular, a cross-sectional design and inherent temporal ambiguity are limitations for causality determination. As strengths, the study has random sampling of the general population, adjustment for multiple confounding factors, and atopy research using a robust method, such as SPTs, although specific serum IgE to allergens was not determined.

In summary, obesity and some elements of the metabolic syndrome can be added to the list of factors that are associated with higher IgE concentrations [1-3]. Further studies are needed to investigate the mechanisms underlying such association. 


\section{Statement of Ethics}

The A-Estrada Glycation and Inflammation Study (AEGIS) is available at www.clinicaltrials.gov, code NCT01796184. The study was approved by the Regional Ethics Committee (code 2010-315). Written informed consent was obtained from all participants.

\section{Conflict of Interest Statement}

The authors report no conflicts of interest in relation to this manuscript.

\section{Funding Sources}

The study was supported by grants from the Carlos III Institute of Health (Instituto de Salud Carlos III, PI16/01,404 and PI16/01,395), the Spanish Network for Additive Disorders (Red de Trastornos Adictivos, RD16/0017/0018, Spanish Ministry of
Health), the Spanish Network for Preventive Activity \& Health Promotion Research in Primary Care (Red de Actividades Preventivas $y$ de Promocion de Salud en Atención Primaria, RD16/0007/0006), and the European Regional Development Fund (FEDER). A personal grant from the Alfonso Martín Escudero Foundation was awarded to I.C.

\section{Author Contributions}

Francisco Gude and Arturo González-Quintela are the principal investigators of the study. They developed the design of the study and were actively involved in the search of funding, staff selection, supervision of the steps of the study, statistical analyses, and interpretation of results. Iago Carballo and Manuela AlonsoSampedro were responsible for selection of samples and laboratory studies. Elena González-Conde participated in the interpretation of the results. Juan Sánchez-Castro was mainly responsible for the recruitment of patients, and Carmen Vidal participated in the design of the allergy tests and their interpretation. All authors discussed and approved the manuscript.

\section{References}

1 Stokes J, Casale TB, Bochner BS, Feldweg AM. The biology of IgE. In: Bochner BS, Feldweg AM, editors. UpToDate. Wolters Kluwer: UpToDate Inc.; 2020.

2 Smith PH, Ownby D. Clinical significance of immunoglobulin E. In: Adkinson NF, Brochner BS, Busse WW, Holgate ST, Lemanske RF, Simons FER, editors. Middleton's allergy principles and practice. Philadelphia, USA: Mosby Elsevier; 2009. p. 845-57.

3 Omenaas E, Bakke P, Elsayed S, Hanoa R, Gulsvik A. Total and specific serum IgE levels in adults: relationship to sex, age and environmental factors. Clin Exp Allergy. 1994;24(6): 530-9.

4 Barbee RA, Halonen M, Lebowitz M, Burrows B. Distribution of IgE in a community population sample: correlations with age, sex, and allergen skin test reactivity. J Allergy Clin Immunol. 1981;68(2):106-11.

5 Gonzalez-Quintela A, Vidal C, Gude F. Alcohol, IgE and allergy. Addict Biol. 2004;9(3-4): 195-204.

6 Alvela-Suarez L, Campos J, Carballo I, Gomez-Rial J, Vidal C, Lombardero M, et al. False-positive results of serological tests for allergy in alcoholic patients. J Investig Allergol Clin Immunol. 2019;29:213-21.

7 Lombholt FK, Nielsen SF, Nordestgaard BG. High alcohol consumption causes high IgE levels but not high risk of allergic disease. J Allergy Clin Immunol. 2016;138:1404-13.

8 Burrows B, Halonen M, Barbee RA, Lebowitz MD. The relationship of serum immunoglobulin E to cigarette smoking. Am Rev Respir Dis. 1981;124(5):523-5.
9 GBD 2015 Obesity Collaborators, Afshin A, Forouzanfar MH, Reitsma MB, Sur P, Estep $\mathrm{K}$, et al. Health effects of overweight and obesity in 195 countries over 25 years. N Engl J Med. 2017;377(1):13-27.

10 Odegaard JI, Chawla A. Type 2 responses at the interface between immunity and fat metabolism. Curr Opin Immunol. 2015;36:67-72.

11 Duffen J, Zhang M, Masek-Hammerman K, Nunez A, Brennan A, Jones JEC, et al. Modulation of the IL-33/IL-13 axis in obesity by IL13Ra2. J Immunol. 2018;200(4):1347-59.

12 Zhang X, Zheng J, Zhang L, Liu Y, Chen GP, Zhang HP, et al. Systemic inflammation mediates the detrimental effects of obesity on asthma control. Allergy Asthma Proc. 2018; 39(1):43-50.

13 Dandona P, Ghanim H, Monte SV, Caruana JA, Green K, Abuaysheh S, et al. Increase in the mediators of asthma in obesity and obesity with type 2 diabetes: reduction with weight loss. Obesity. 2014;22(2):356-62.

14 Binisor ID, Moldovan R, Moldovan I, Andrei AM, Banita MI. Abdominal obesity and type 2 diabetes mellitus are associated with higher seric levels of IL 4 in adults. Curr Health Sci J. 2016;42(3):231-7.

15 Kim MK, Jeong JS, Han K, Baek KH, Song $\mathrm{KH}$, Kwon HS. House dust mite and cockroach specific immunoglobulin E sensitization is associated with diabetes mellitus in the adult Korean population. Sci Rep. 2018;8(1): 2614.

16 Park HJ, Kim EJ, Yoon D, Lee JK, Chang WS, Lim YM, et al. Prevalence of self-reported allergic diseases and IgE levels: a 2010 KNHANES analysis. Allergy Asthma Immunol Res. 2017;9(4):329-39.
17 Visness CM, London SJ, Daniels JL, Kaufman JS, Yeatts KB, Siega-Riz AM, et al. Association of obesity with IgE levels and allergy symptoms in children and adolescents: results from the National Health and Nutrition Examination Survey 2005-2006. J Allergy Clin Immunol. 2009;123(5):1163-4.

18 Jarvis D, Chinn S, Potts J, Burney P; European Community Respiratory Health Survey. Association of body mass index with respiratory symptoms and atopy: results from the European Community Respiratory Health Survey. Clin Exp Allergy. 2002;32(6):831-7.

19 Alende-Castro V, Alonso-Sampedro M, Vazquez-Temprano N, Tuñez C, Rey D, García-Iglesias $\mathrm{C}$, et al. Factors influencing erythrocyte sedimentation rate in adults: new evidence for an old test. Medicine. 2019;98(34): e16816.

20 Expert Panel on Detection, Evaluation and Treatment of High Blood Cholesterol in Adults. Executive summary of third report of the National Cholesterol Education Program (NCEP) expert panel on detection, evaluation, and treatment of high blood cholesterol in adults (adult treatment panel III). JAMA. 2001;285:2486-97.

21 Haahtela T. 6. Skin tests used for epidemiologic studies. Allergy. 1993;48(s14):76-80.

22 Johansson SG, Hourihane JO, Bousquet J, Bruijnzeel-Koomen C, Dreborg S, Haahtela $\mathrm{T}$, et al. A revised nomenclature for allergy. An EAACI position statement from the EAACI nomenclature task force. Allergy. 2001; 56(9):813-24. 
23 Gual A, Martos AR, Lligoña A, Llopis JJ. Does the concept of a standard drink apply to viticultural societies? Alcohol Alcohol. 1999; 34(2):153-60

24 Román-Viñas B, Lourdes Ribas-Barba L, Ngo J, Serra-Majem L. Validity of the international physical activity questionnaire in the Catalan population (Spain). Gac Sanit. 2013;27: 254-7.

25 Appleton SL, Adams RJ, Wilson DH, Taylor AW, Ruffin RE. Central obesity is associated with nonatopic but not atopic asthma in a representative population sample. J Allergy Clin Immunol. 2006;118(6):1284-91.

26 Ronmark E, Andersson C, Nystrom L, Forsberg B, Jarvholm B, Lundback B. Obesity increases the risk of incident asthma among adults. Eur Respir J. 2005;25:282-8.

27 Kronander UN, Falkenberg M, Zetterström $O$. Prevalence and incidence of asthma related to waist circumference and BMI in a Swedish community sample. Respir Med. 2004;98(11): 1108-16.

28 Beuther DA, Sutherland ER. Overweight, obesity, and incident asthma: a meta-analysis of prospective epidemiologic studies. Am J Respir Crit Care Med. 2007;175(7):661-6.

29 Huang SL, Shiao G, Chou P. Association between body mass index and allergy in teenage girls in Taiwan. Clin Exp Allergy. 1999;29(3): 323-9.
30 Schachter LM, Peat JK, Salome CM. Asthma and atopy in overweight children. Thorax. 2003;58(12):1031-5.

31 Han YY, Forno E, Gogna M, Celedón JC. Obesity and rhinitis in a nationwide study of children and adults in the United States. J Allergy Clin Immunol. 2016;137(5):1460-5.

32 Boulet LP. Obesity and atopy. Clin Exp Allergy. 2015;45(1):75-86.

33 Husemoen LL, Glümer C, Lau C, Pisinger C, Mørch LS, Linneberg A. Association of obesity and insulin resistance with asthma and aeroallergen sensitization. Allergy. 2008; 63(5):575-82.

34 Wang Z, Zhang H, Shen XH, Jin KL, Ye GF, Qiu W, et al. Immunoglobulin E and mast cell proteases are potential risk factors of impaired fasting glucose and impaired glucose tolerance in humans. Ann Med. 2013;45(3): 220-9.

35 Wang Z, Zhang H, Shen XH, Jin KL, Ye GF, Qian L, et al. Immunoglobulin E and mast cell proteases are potential risk factors of human pre-diabetes and diabetes mellitus. PLoS One. 2011;6(12):e28962.
36 Guo X, Meng G, Liu F, Zhang Q, Liu L, Wu $\mathrm{H}$, et al. Serum levels of immunoglobulins in an adult population and their relationship with type 2 diabetes. Diabetes Res Clin Pract. 2016;115:76-82.

37 Hersoug LG, Linneberg A. The link between the epidemics of obesity and allergic diseases: does obesity induce decreased immune tolerance? Allergy. 2007;62(10):1205-13.

38 Surendar J, Mohan V, Rao MM, Babu S, Aravindhan $\mathrm{V}$. Increased levels of both Th1 and Th2 cytokines in subjects with metabolic syndrome (CURES-103). Diabetes Technol Ther. 2011;13(4):477-82.

39 Ingelsson E, Hulthe J, Lind L. Inflammatory markers in relation to insulin resistance and the metabolic syndrome. Eur J Clin Invest. 2008;38(7):502-9.

40 Zhang J, Shi GP. Mast cells and metabolic syndrome. Biochim Biophys Acta. 2012;1822(1): 14-20.

41 Lippi G, Cervellin G, Sanchis-Gomar F. Immunoglobulin $\mathrm{E}(\mathrm{IgE})$ and ischemic heart disease. Which came first, the chicken or the egg? Ann Med. 2014;46(7):456-63.

42 Zhang X, Li J, Luo S, Wang M, Huang Q, Deng $\mathrm{Z}$, et al. IgE contributes to atherosclerosis and obesity by affecting macrophage polarization, macrophage protein network, and foam cell formation. Arterioscler Thromb Vasc Biol. 2020;40(3):597-610. 